\title{
Risk Factors Associated With Childhood Stunting in Rwanda: A Secondary Analysis of the 2014 Nutrition, Markets and Gender (NMG) Survey
}

\author{
Lauriane Nyiraneza ${ }^{1,2}$, Rex Wong ${ }^{2}$, Olushayo Olu ${ }^{1}$, Marie-Rosette Nahimana ${ }^{1}$, Eliud Birachi ${ }^{3}$, August Musoni ${ }^{4}$, \\ Chantal Gegout ${ }^{1} \&$ Jenae Logan ${ }^{2}$ \\ ${ }^{1}$ World Health Organization, Rwanda \\ ${ }^{2}$ University of Global Health Equity, Rwanda \\ ${ }^{3}$ International Center for Tropical Agriculture \\ ${ }^{4}$ Rwanda Agriculture Board \\ Correspondence: Lauriane Nyiraneza, World Health Organization, Rwanda Office, Rwanda.
}

Received: January 12, 2019

Accepted: March 7, 2019

Online Published: March 11, 2019

doi:10.5430/jms.v10n2p34

URL: https://doi.org/10.5430/jms.v10n2p34

\begin{abstract}
Childhood stunting can have negative health, social, and economic outcomes. In 2015, 37.9\% of children under the age of five were stunted in Rwanda. This study aimed to understand the risk factors associated with stunting specific to Rwanda in order to inform effective interventions.

The analysis found higher odds of stunting among the children of mothers who had no education compared to those with secondary education (OR: 2.1, 95\% CI: 1.34-3.36), who did not take sufficient quantities of food during the pregnancy (OR: $1.3,95 \% \mathrm{CI}: 1.07-1.65)$ or did not consume a diverse diet during pregnancy (OR: $1.3,95 \% \mathrm{CI}$ : 1.12-1.73). Children living in households with two or more children under two years of age (OR: $2.4,95 \% \mathrm{CI}$ : 1.35-2.50), born with low birth weight (OR: 2.8, 95 CI: 1.67-4.27), born preterm (OR: 4.1, 95 CI: 1.96-8.70), not consuming animal proteins (OR: 1.7 CI: 1.49-2.02) and not drinking treated water (OR: 1.6, CI: 1.07-2.23) all have higher odds of developing stunting. Children living in households with low dietary diversity also had higher odds of stunting (OR: 2.2 CI: 1.23-3.88).

The results of the analysis suggested that women should be educated to modify their feeding behavior. Educating women can potentially influence their decision-making related to antenatal care (ANC) service attendance and to their own as well as their children's nutrition needs. Appropriate birth spacing should be encouraged. Providing nutritional supplements to mothers at ANC appointments, increasing access to diverse food groups, and providing nutritional care for babies with low birth weight are potential interventions to address the issue of childhood stunting in Rwanda.
\end{abstract}

Keywords: childhood stunting, risk factors, Rwanda, case control study, nutrition, markets and gender survey

\section{Introduction}

Malnutrition affects most of the world's population at some point in their lifecycle, regardless of geographic location, age, wealth status, or gender (Research Institute, 2014). Decades of research and studies have shown that malnutrition bears many negative consequences for physical growth, morbidity, mortality, cognition, reproduction, learning and intellectual performance, work capacity and productivity (Stewart et al, 2013).

Malnutrition comes in many forms. The most common type of malnutrition in low-income countries is under-nutrition, causing wasting and stunting. Childhood stunting, a condition in which a child is too short for his or her age according to the World Health Organization (WHO) child growth standards (WHO, 2014a; Sudfeld et al., 2015), is a major public health issue that has a negative impact on human capital development. Stunting in early life, from conception to the age of two, can result in poor cognitive, psychomotor and mental development, poor educational performance, reduced productivity and subsequently low wages, as well as increased risk of nutrition-related chronic diseases in adult life (Danaei G. et al, 2016; Wilcox \& Hirshkowitz, 2015; Sudfeld et al, 2015; Rolfe. et al., 2018). The direct health care cost for stunting as well as for the stunting-related chronic diseases developed later in their adulthood can pose a significant economic burden to the individuals or their families (Rolfe. et al., 2018). 
The prevalence of stunting in Africa is one of the highest in the world, and the recent trend is stagnation rather than progress (Wondimagegn et al, 2014). Out of 151 million children under the age of five years who are stunted globally, about 59 million (39\%) are in Africa (UNICEF, WHO, World Bank, 2018; Uwiringiyimana et al,2018). Although the overall prevalence of stunting has dropped from $38.3 \%$ in 2000 to $30.5 \%$ in 2017 in Africa overall and from $45.7 \%$ to $35.6 \%$ in Eastern Africa during the same period (UNICEF, WHO, World Bank, 2018), the prevalence remains high. There is a critical need to address stunting in order to achieve sustainable development.

The government of Rwanda is committed to reducing the prevalence of stunting and has implemented various national strategies. One of the more notable strategies was the "First Thousand Days" mass campaign launched in September 2013. The campaign is a multi-pronged intervention to improve food security for the families including kitchen gardens promotions, animal breeding, cow milk distribution to school children, immunization, as well as maternal, infant and young child nutrition sensitization programs (Ministry of Agriculture and Animal Resources, 2014). With this commitment, Rwanda reduced the prevalence of stunting among children under the age of five from $45.3 \%$ in 2005 to $38 \%$ in 2015 (NISR - MOH and ICF International, 2015). The country has set ambitious targets to further reduce the prevalence to $29.9 \%$ by 2020 and to $19 \%$ by 2024 (MOH, 2018).

Studies have identified many causes of and risk factors for stunting. Common causes include inadequate food and protein intake as well as lack of access to health care and general care (Sudfeld et al., 2015; Danaei, et al, 2016). Some risk factors, especially in Africa, include living in poverty and in places where infectious diseases are prevalent, inadequate complementary feeding and breastfeeding practices, low household income, mothers with low education level, and unemployment (Mamabolo et al, 2005). Babies born prematurely and with low birth weight are also having higher risk of developing stunting (Mamabolo et al, 2005; WHO, 2019a).

Given the negative impact of stunting on individual growth, socio-economic development, and achieving the sustainable development goals, effective programs to reduce stunting must be developed. Although many malnutrition-related studies have been conducted in various countries, only one study was in Rwanda identifying the risk factors associated with being underweight (Mukabutera, et al, 2016). In order to design effective programs to further reduce stunting, understanding the risk factors associated with stunting specific to Rwanda is necessary. This study was carried out to address this information gap to provide evidence and recommendations to support decision makers and program managers in designing effective interventions in Rwanda.

\section{Methods}

\subsection{Data}

This study utilized data from the 2014 Nutrition, Markets and Gender Survey conducted by International Center for Tropical Agriculture (CIAT) in nine districts in Rwanda with high prevalence of stunting in children under 5 years. The survey utilized a multistage cluster sampling method to select the districts, then 16 villages were randomly selected per sector in each district. All children under 60 months of age in the villages were screened for stunting and anemia. In the final dataset, 2755 of children were within the age group of 0 to 24 months. Among them, 1373 were stunted (cases) and 1382 were without stunting (controls).

\subsection{Variables}

\subsubsection{Dependent Variables}

Stunting was used as the dependent variable in our analysis, defined as follows: the height-for-age Z-score was calculated using the WHO Child Growth Standards (WHO, 2014). Children aged 0-24 months whose height-for-age Z-scores were below two standard deviations from the median of the reference population are considered stunted (case).

\subsubsection{Independent Variables}

Independent variables assessed as risk factors included sociodemographic variables, economic status, maternal and child health variables, and food consumption information.

\subsection{Data Analysis}

Descriptive statistics were calculated to summarize the socio-demographic and economic characteristics of the study population. The Pearson Chi-square test was used to evaluate the associations between different potential risk factors and stunting. All factors that were found significant (P-value at 0.05) in bivariate analysis were included in the multiple logistic regression model. The adjusted Wald test was then used to assess the significance of each variable. All tests were conducted using SPSS v.21, with significant levels set at 95\% confidence interval (95\% CI) and p-value at 0.05 . 


\section{Results}

A total of $1373(49.8 \%)$ cases and $1382(50.2 \%)$ controls were extracted from the dataset (Table 1).

Table 1. Distribution of stunting by socio demographic characteristic of respondents

\begin{tabular}{|c|c|c|c|c|}
\hline Variable & & Control \# (\%) & Cases \# (\%) & P-value \\
\hline Sample size & & $1382(50.2 \%)$ & $1373(49.8 \%)$ & \\
\hline \multirow[t]{2}{*}{ Residence } & Rural & $994(71.9 \%)$ & $1031(75.1 \%)$ & 0.06 \\
\hline & Urban & $388(28.1 \%)$ & $342(24.9 \%)$ & \\
\hline \multirow[t]{5}{*}{ Wealth index } & Poorest & $275(19.9 \%)$ & $275(20 \%)$ & $<0.001 * *$ \\
\hline & Poor & $249(18 \%)$ & $308(22.4 \%)$ & \\
\hline & Middle & $266(19.2 \%)$ & $285(20.8 \% 0$ & \\
\hline & Rich & $274(19.8 \%)$ & $280(20.4 \%)$ & \\
\hline & Richest & $318(23.0 \%)$ & $225(16.4 \%)$ & \\
\hline \multirow[t]{5}{*}{ Marital status } & Married & $1126(81.5 \%)$ & $1086(79.1 \%)$ & 0.26 \\
\hline & Widowed & $49(3.5 \%)$ & $66(4.8 \%)$ & \\
\hline & Divorced & $27(2.0 \%)$ & $38(2.8 \%)$ & \\
\hline & Partnered & $141(10.2 \%)$ & $147(10.7 \%)$ & \\
\hline & Never married & $39(2.8 \%)$ & $36(2.6 \%)$ & \\
\hline \multirow{2}{*}{$\begin{array}{llr}\begin{array}{l}\text { Household } \\
\text { covered } \\
\text { insurance }\end{array} & & \text { members } \\
\end{array}$} & $<50 \%$ & $493(35.7 \%)$ & $584(42.5 \%)$ & $<0.001 * *$ \\
\hline & $50-100 \%$ & $889(64.4 \%)$ & $789(57.5 \%)$ & \\
\hline \multirow{3}{*}{$\begin{array}{l}\text { Education of head of } \\
\text { household }\end{array}$} & No education & $316(22.9 \%)$ & $391(28.5 \%)$ & $<0.001 * *$ \\
\hline & Primary & $844(61.1 \%)$ & $853(62.1 \%)$ & \\
\hline & Secondary and high & $222(16.1 \%)$ & $129(9.4)$ & \\
\hline \multirow[t]{4}{*}{ Education of mother } & No education & $302(21.9 \%)$ & $360(26.2 \%)$ & $<0.001 * *$ \\
\hline & Primary & $765(55.4 \%)$ & $762(55.5 \%)$ & \\
\hline & Secondary and high & $205(14.8 \%)$ & $122(8.9 \%)$ & \\
\hline & Don't know & $110(8.0 \%)$ & $129(9.4 \%)$ & \\
\hline \multirow{2}{*}{$\begin{array}{l}\text { Number of children below } 2 \\
\text { years in the household }\end{array}$} & One children & $856(61.9 \%)$ & $781(56.9 \%)$ & $0.006^{* *}$ \\
\hline & Two or more & $526(38.1 \%)$ & $592(43.1 \%)$ & \\
\hline \multirow[t]{2}{*}{$\dagger$ Sex of reference child } & Male & $760(54.9 \%)$ & $745(58.7 \%)$ & 0.69 \\
\hline & Female & $553(42.1 \%)$ & $525(41.3 \%)$ & \\
\hline Birth weight & Low $(<2.5 \mathrm{~kg})$ & $45(3.3 \%)$ & $169(12.5 \%)$ & $<0.001 * *$ \\
\hline $\begin{array}{l}\text { Premature at birth } \quad(<8 \\
\text { months })\end{array}$ & Premature & $18(1.3 \%)$ & $47(3.4 \%)$ & $<0.001 * *$ \\
\hline \multirow[t]{2}{*}{$\begin{array}{l}\text { In the past } 6 \text { months, child } \\
\text { took: }\end{array}$} & Anti-malaria & $1238(89.6 \%)$ & $1220(88.9 \%)$ & 0.15 \\
\hline & Vitamin A & $219(15.8 \%)$ & $203(14.8 \%)$ & 0.18 \\
\hline In 2014, child took: & Iron supplements & $133(9.6 \%)$ & $131(9.5 \%)$ & 0.27 \\
\hline During the reference child's & Mother ate diverse diet & $940(69.3 \%)$ & $792(59 \%)$ & $<0.001 * *$ \\
\hline
\end{tabular}




\begin{tabular}{lllll}
\hline pregnancy & Household had enough food & $806(58.3 \%)$ & $631(46.0 \%)$ & $<0.001^{* *}$ \\
\hline $\begin{array}{l}\text { Household } \begin{array}{l}\text { consumption } \\
\text { days }\end{array} \\
\text { food the past }\end{array}$ & Cereal and tubers & $1237(89.5 \%)$ & $1197(87.2 \%)$ & 0.21 \\
\cline { 2 - 5 } & Pulses and legumes & $1169(84.6 \%)$ & $1123(81.8 \%)$ & 0.21 \\
\cline { 2 - 5 } & Vegetable & $941(68.1 \%)$ & $920(67.0 \%)$ & 0.89 \\
\cline { 2 - 5 } & Fruits & $401(29.0 \%)$ & $338(27.6 \%)$ & $0.02^{* *}$ \\
\cline { 2 - 5 } & Animal sources of protein & $266(21.2 \%)$ & $193(15.3 \%)$ & $<0.001^{* *}$ \\
\cline { 2 - 5 } & Milk and other diary & $316(25.1 \%)$ & $230(18.8 \%)$ & $<0.001^{* *}$ \\
\cline { 2 - 5 } & Oil, fat and butter & $509(41.6 \%)$ & $781(62.1 \%)$ & 0.06 \\
\hline Household diet diversity & Low & $822(65.4 \%)$ & $884(72.2 \%)$ & $<0.001^{* *}$ \\
\hline & Medium & $329(26.2 \%)$ & $292(23.8 \%)$ & \\
\hline & High & $692(64.6 \%)$ & $561(54.6 \%)$ & $<0.001^{* *}$ \\
\hline Child drinks & Treated water & $49(4.0 \%)$ & \\
\hline
\end{tabular}

** statistically significant at $\mathrm{P}=0.05 ; \dagger \quad 103$ missing data in case and 69 in control group

The results of the bivariate analyses showed the following factors were statistically significantly associated with stunting $(\mathrm{p}<0.05)$ : Wealth index, household members covered by medical insurance, education of head of household or mother, number of children below 2 years in the household, birth weight, prematurity at birth, mother ate diverse diet during pregnancy, household had enough food during pregnancy, the household ate fruits, animal protein, milk or dairy, diet diversity, and the children drank treated water (Table 1).

Multivariate analysis found nine factors that were significantly associated with increased odds of stunting among children aged 0 - 24 months in Rwanda at $\mathrm{p}=0.05$. In comparison with children whose mothers had secondary or higher education, the odds of stunting was 2.1 times higher among children whose mothers had no education (OR: 2.1, 95\% CI: 1.34-3.36, $\mathrm{P}<0.010)$ and 1.3 times higher for those whose mother had primary education (OR: $2.1,95 \%$ CI: 1.34-3.36, P <0.010). Children living in households with two or more children under two years of age had 2.4 times higher odds of stunting compared with children living in households with only one child under two years of age (OR: 2.4, 95\% CI: 1.35-2.50; $\mathrm{P}<0.003$ ). The odds of stunting among children who were born with low birth weight were 2.8 times higher than among children who had normal birth weight (OR: 2.8, 95 CI: 1.67-4.27; P< 0.001). Preterm children had 4.1 times higher odds of stunting than children who were born full term (OR: 4.1, 95 CI: 1.96-8.70; P< 0.001). Children whose mothers did not take sufficient quantities of food during the pregnancy had 1.3 times higher odds of stunting than those whose mothers who took sufficient quantities of food during pregnancy (OR:1.3, 95\% CI:1.07-1.65; $\mathrm{P}=0.010$ ). The odds of stunting among children whose mothers did not consume a diverse diet during pregnancy were 1.4 times higher than among those whose mothers had sufficient dietary diversity during pregnancy (OR:1.3, 95\% CI: 1.12-1.73; $\mathrm{P}=0.004)$. Children who did not consume animal proteins in the seven days preceding the survey had 1.7 times higher odds of stunting compared to those who had consumed animal protein (OR: 1.7 CI: 1.49-2.02; P=0.020). Compared to children living in households with high dietary diversity, children who lived in households with low dietary diversity had 2.2 times higher odds of stunting (OR: 2.2 CI: 1.23-3.88; $\mathrm{P}=0.007$ ) and those in households with medium dietary diversity had 2.5 times higher odds of stunting (OR: $2.5 \mathrm{CI}$ : 1.16-5.31; $\mathrm{P}=0.010$ ). The odds of stunting among children who drank untreated drinking water were 1.6 times higher than those who drank treated water (OR: 1.6, CI: $1.07-2.23 ; \mathrm{P}=0.020$ ) (Table 2).

Table 2. Results of multivariate analysis

\begin{tabular}{lllll}
\hline Variables & & AOR & 95\% CI & P-value \\
\hline \multirow{2}{*}{ Wealth index of household (Ref = Richest) } & Poorest & 1.1 & $0.82-1.42$ & 0.670 \\
\cline { 2 - 5 } & Poor & 0.9 & $0.66-1.35$ & 0.760 \\
\hline
\end{tabular}




\begin{tabular}{|c|c|c|c|c|}
\hline & Middle & 0.8 & $0.56-1.14$ & 0.220 \\
\hline & Rich & 1.3 & $0.92-1.83$ & 0.120 \\
\hline $\begin{array}{l}\text { More than } 50 \% \text { of household members with } \\
\text { medical insurance (Ref }=\text { yes) }\end{array}$ & $<50 \%$ & 0.9 & $0.76-1.16$ & 0.570 \\
\hline \multirow{2}{*}{$\begin{array}{l}\text { Education of head of household ( } \mathrm{Ref}=\text { Secondary } \\
\text { and higher) }\end{array}$} & No school & 0.7 & $0.37-1.21$ & 0.100 \\
\hline & Primary & 0.9 & $0.60-1.35$ & 0.600 \\
\hline \multirow{2}{*}{$\begin{array}{l}\text { Education of mother (Ref }=\text { Secondary and } \\
\text { higher) }\end{array}$} & No school & 2.1 & $1.34-3.36$ & $0.010^{* *}$ \\
\hline & Primary & 1.3 & $1.24-2.02$ & $0.020^{* *}$ \\
\hline Household with children under 2 years $(\operatorname{Ref}=1)$ & Two or more & 2.4 & $1.35-1.50$ & $0.003^{* *}$ \\
\hline Prematurity at birth $($ Ref $=$ term $)$ & Premature ( $<8$ months $)$ & 4.1 & $1.96-8.70$ & $<0.001 * *$ \\
\hline Birth weight $(\mathrm{Ref}=$ Normal, $\geq 2.5 \mathrm{~kg})$ & Low $(<2.5 \mathrm{~kg})$ & 2.8 & $1.67-4.27$ & $<0.001 * *$ \\
\hline \multirow{2}{*}{ Household dietary diversity $(\operatorname{Ref}=$ high $)$} & Medium & 2.5 & $1.16-5.31$ & $0.010 * *$ \\
\hline & Low & 2.2 & $1.23-3.88$ & $0.007 * *$ \\
\hline Had enough food during pregnancy $($ Ref $=$ yes $)$ & No & 1.3 & $1.07-1.65$ & $0.010^{* *}$ \\
\hline Dietary diversity during pregnancy $(\operatorname{Ref}=$ yes $)$ & No & 1.4 & $1.12-1.73$ & $0.004 * *$ \\
\hline Child consumed animal proteins $(\operatorname{Ref}=$ yes $)$ & No & 1.7 & $1.49-2.02$ & $0.020^{* *}$ \\
\hline Child consumed a milk/other diary $(\operatorname{Ref}=$ yes $)$ & No & 1.0 & $0.69-1.32$ & 0.700 \\
\hline Child consumed the fruits $(\operatorname{Ref}=$ yes $)$ & No & 0.9 & $0.66-1.22$ & 0.520 \\
\hline Child drank treated water $(\operatorname{Ref}=$ yes $)$ & No & 1.6 & $1.07-2.23$ & $0.020^{* *}$ \\
\hline
\end{tabular}

** Statistically significant at $\mathrm{P}=0.05$

\section{Discussion}

The present study assessed the risk factors associated with stunting in children age 0 to 24 months in Rwanda. The analysis found that low birth weight and gestational age at birth were major predictors of stunting in children. These findings are consistent with the findings of other similar studies (Danaei, et al, 2016; Chirande et al., 2015). Low birth weight is generally related to preterm birth, and many studies have indicated that preterm babies or babies with low birth can catch up on growth with sufficient breast feeding (WHO 2019b, Capt, Devi, \& Mshl, 2009). However, in LMIC, many mothers may not have enough food or proper diet themselves during pregnancy, as reflected from the results of our analysis. In resource-limited settings, preterm/low birth weight babies inevitably have higher risk of developing stunting.

Poor nutritional status and inadequate nutritional intake for women during pregnancy is also a well-known cause of low birth weight (WHO, 2019a). Pregnancy requires more energy and more nutrients than the preconception phase. Appropriate food quantities and dietary diversity are important to fetal development and pregnancy outcomes. Our analysis showed mothers who lacked dietary diversity and had insufficient quantities of food during their pregnancies had higher odds of having stunted children. Similar findings have been reported in other studies in Ethiopia and Uganda (Chirande et al., 2015; Shinsugi et al., 2015).

Similar to other studies, our analysis showed that the education level of mothers was also significantly associated with stunting (Mukabutera, et al, 2016; Chirande et al., 2015; Demissie, 2013). Mothers play significant roles in managing the health of their own as well as of their children (Glewwe \& Kremer, 2006; Aemro, Mesele, Birhanu, Atenafu, 2013). Educated mothers are more likely to seek information on how to care for their children, including proper feeding and health care (Glewwe \& Kremer, 2016). Mothers who are educated were more likely to ensure their children received appropriate dietary diversity and meal frequency (Aemro, 2013). They may be more proficient in taking care of themselves, which is another important factor since our results showed that the food consumption and diversity during their pregnancy can affect the odds of children having stunting. In our analysis, children who were fed with animal protein and drank treated water had lower odds of stunting. Animal proteins contain nutrients and micronutrients which are essential for child growth (Shinsugi et al., 2015; Bukusuba, Kaaya, \& Atukwase, 2017). Treatment of drinking 
water has a significant impact on the reduction of morbidity related to infectious and diarrheal diseases among children less than 24 months. Diarrhea can cause loss of appetite and hinder nutrient absorption, which in turn can cause growth retardation in infants and children (Nkurunziza, Meessen, Van geertruyden, \& Korachais, 2017; Sharma, Arvind Kumar., Baig, Vaseem, Yadev, 2010). Mothers who were educated are more likely to be empowered to make decisions to provide children such basic necessities. Educated mothers not only are more capable of reading medical instructions for treatment and applying the treatments when the children are sick, they are also more receptive to modern medicine (Abuya, et al, 2012).

One other risk factor suggested from our analysis was households having more than one young child (less than two years old). Similar findings have been reported in other developing countries (Nkurunziza, Meessen, Van geertruyden, Korachais, 2017; Mbuya, Chidem, Chasekwa, Mishra, 2010). When families have more children competing for resources, the odds of stunting for the children is understandably higher. Studies have shown that high fertility is harmful to womens' health, limiting the womens' ability to work, reducing their contribution to household income, and lowering their utilization of ANC services (Greene and Merrick, 2005; Joshi \& Schultz, 2007; Longwe-Ngwira, 2014; Abosse, Woldie, Ololo, 2010).

The findings of this study suggest that educating women can have multiple benefits that can contribute to the reduction of stunting in children. Educated women not only can take better care of themselves but also their children. Mothers' level of education has been shown to influence the use of ANC, with more educated women being more likely to attend ANC (World Bank, 1994). Studies have shown that ANC can reduce the chance of babies being born with low birth weight (Ahmed, 1992; Mahumud, 2017). Educating parents to practice child spacing can potentially improve households' financial positions and ability to provide for children's nutritional needs, allowing women to have more available time to care for children (World Bank, 1994).

Since this study utilized a secondary data analysis approach to identify the factors associated with stunting in children between 0 and 24 months old in Rwanda, the study was limited to what was available in the data set. Other factors potentially associated with stunting could not be analyzed if the original dataset did not include them. Some missing values in the data set may also have affected the results of the analysis. The original dataset only included nine districts with high prevalence of stunting in Rwanda, the results may not be representative of the whole country.

\section{Conclusions}

Our analysis identified a number of factors associated with child stunting. The results suggest that women should consume sufficient and diverse foods during pregnancy and that children should be fed with animal protein and treated water. Providing women with the knowledge about nutrition, ANC, and health care is important, as educating women can influence their decision making related to ANC service attendance and to their own as well as their children's nutrition needs. Birth spacing should be encouraged to reduce the burden on family imposed by having multiple young infants. This study suggests a number of possible interventions that could be used to further reduce stunting in Rwanda. Among them are providing nutritional supplements to mothers at ANC appointments, increasing access to diverse food groups and providing nutritional care for babies, especially for those with low birth weight. Interventions aiming to improve access to safe drinking water to reduce diarrheal and parasitic diseases can also help reduce growth retardation in infants and young children in Rwanda. Educating and empowering women must be the core of any program, as they are often the primary care providers for children.

\section{Acknowledgement}

The authors would like to thank the WHO, UNICEF, WFP and FAO for providing the financial and technical support to conduct the survey and allowed us to use their data to conduct secondary data analysis. We also express our gratitude to International Center for Tropical Agriculture, Ministry of Agriculture, and Ministry of Health for approving our access to the data.

\section{References}

Abosse, Z., Woldie, M., \& Ololo, S. (2010, July). Factors influencing antenatal care service utilization in Hadiya zone. Ethiop J Health Sci, 20(2), 75-82. https://doi.org/10.1186/1471-2431-12-80

Abuya, B. A., Ciera, J., \& Kimani-Murage, E. (2012). Effect of mother's education on child's nutritional status in the slums of Nairobi. BMC Pediatrics, 12(1), 80.

Aemro, M., Mesele, M., Birhanu, Z., \& Atenafu, A. (2013). Dietary Diversity and Meal Frequency Practices among Infant and Young Children Aged 6 - 23 Months in Ethiopia: A Secondary Analysis of Ethiopian Demographic and Health Survey 2011. Journal Nutr Metab, 8. https://doi.org/10.1155/2013/782931 
Ahmed, F. U., \& Das, A. M. (1992). Beneficial effects. Three ANC visits might be the divergent point in lowering low birth weight babies. Bangladesh. Integration, (33), 50-3.

Bukusuba, J., Kaaya, A. N., \& Atukwase, A. (2017). International Journal of Nutrition, (3).

Capt, D. S. G., Devi, N., \& Mshl, T. (2009). Exclusive breastfeeding in low birth weight babies. Medical Journal Armed Forces India, 65(3), 208-212. https://doi.org/10.1016/S0377-1237(09)80004-X

Chirande, L., Charwe, D., Mbwana, H., Victor, R., Kimboka, S., Issaka, A. I., et al. (2015). Determinants of stunting and severe stunting among under-fives in Tanzania: Evidence from the 2010 cross-sectional household survey. BMC Pediatr, 15(1), 1-13. http://dx.doi.org/10.1186/s12887-015-0482-9

Danaei, G., Andrews, K. G., Sudfeld, C. R., Fink, G., McCoy, D. C., Peet, E., et al. (2016). Risk Factors for Childhood Stunting in 137 Developing Countries: A Comparative Risk Assessment Analysis at Global, Regional, and Country Levels. PLoS Med, 13(11), 1-18. https://doi.org/10.1371/journal.pmed.1002164

Demissie, S. (2013). Magnitude and Factors Associated with Malnutrition in Children 6-59 Months of Age in Pastoral Community of Dollo Ado District, Somali Region, Ethiopia. Sci J Public Heal, 1(4), 175. https://doi.org/10.11648/j.sjph.20130104.12

Glewwe, P., \& Kremer, M. (2006). Chapter 16 Schools, Teachers, and Education Outcomes in Developing Countries. Handb Econ Educ, 2(06), 945-1017. https://doi.org/10.1016/S1574-0692(06)02016-2

Greene, M., \& Merrick, T. (n.d.). Poverty Reduction: Does Family Planning Matter?. Washington, DC: World Bank.

Joshi, S., \& Schultz, T. P. (2007). Family Planning as an Investment in Development: Evaluation of a Program's Consequences in Matlab, Bangladesh. Center Discussion Paper no. 951, Economic Growth Center, Yale University.

Longwe-Ngwira, A. (2014, November). Family planning in Sub-Saharan Africa: a missed opportunity for economic growth and poverty alleviation. Population Reference Bureau. Retrieved from https://assets.prb.org/pdf14/family-planning-in-sub-saharan-africa.pdf

Mahumud, R. A., Sultana, M., \& Sarker, A. R. (2017). Distribution and determinants of low birth weight in developing countries. Journal of Preventive Medicine and Public Health, 50(1), 18. https://doi.org/10.3961/jpmph.16.087

Mamabolo, R. L., Alberts, M., Steyn, N. P., Delemarre-van de Waal, H. A., \& Levitt, N. S. (2005). Prevalence and determinants of stunting and overweight in 3-year-old black South African children residing in the Central Region of Limpopo Province, South Africa. Public Health Nutrition, 8(05), 501-508. https://doi.org/10.1079/PHN2005786

Mbuya, M. N. N., Chidem, M., Chasekwa, B., \& Mishra, V. (2010). Biological, Social, and Environmental Determinants of Low Birth Weight and Stunting among Infants and Young Children in Zimbabwe. Zimbabwe Work Paper, (7).

Ministry of Agriculture and Animal Resources, Ministry of Health, Ministry of Local Government. (2014). National Food and Nutrition Policy 2013- 2018. Republic of Rwanda: Kigali.

Ministry of Health. (2018, July). Rwanda Fourth Health Sector July 2018 - June 2024.

Mukabutera, A., Thomson, D. R., Hedt-Gauthier, B. L., Basinga, P., Nyirazinyoye, L., \& Murray, M. (2016). Risk factors associated with underweight status in children under five: an analysis of the 2010 Rwanda Demographic Health Survey (RDHS). BMC Nutr, 2(1), 40. https://doi.org/10.1186/s40795-016-0078-2

NISR - MOH and ICF International. (2015). Rwanda Demographic and Health Survey 2014-15 Final Report. Kigali.

Nkurunziza, S., Meessen, B., Van Geertruyden, J. P., \& Korachais, C. (2017). Determinants of stunting and severe stunting among Burundian children aged 6-23 months: Evidence from a national cross-sectional household survey, 2014. BMC Pediatr, 17(1), 1-14. https://doi.org/10.1186/s12887-017-0929-2

Research Institute. (2014). Global Nutrition Report. https://doi.org/10.2499/9780896295643

Rolfe, E. D. L., de França, G. V. A., Vianna, C. A., Gigante, D. P., Miranda, J. J., Yudkin, J. S., ... Ong, K. K. (2018). Associations of stunting in early childhood with cardiometabolic risk factors in adulthood. PloS One, 13(4), e0192196. https://doi.org/10.1371/journal.pone.0192196 
Sharma, A. K., Baig, V. N., Yadav, A. K., Bha-Radwaj, A. K., \& Singh, R. (2016). Prevalence and Risk Factors for Stunting Among Tribal Under-Five Children at South-West, Rajasthan, India. Ntl J Community Med, 7(6), 461-467.

Shinsugi, C., Matsumura, M., Karama, M., Tanaka, J., Changoma, M., \& Kaneko, S. (2015). Factors associated with stunting among children according to the level of food insecurity in the household: A cross-sectional study in a rural community of Southeastern Kenya Global health. BMC Public Health, 15(1), 1-10. https://doi.org/10.1186/s12889-015-1802-6

Stewart, C. P., Iannotti, L., Dewey, K. G., Michaelsen, K. F., \& Onyango, A. W. (2013). Contextualising complementary feeding in a broader framework for stunting prevention. Maternal and Child Nutrition, 9(S2), 27-45. https://doi.org/10.1111/mcn.12088

Sudfeld, C. R., Charles McCoy, D., Danaei, G., Fink, G., Ezzati, M., Andrews, K. G., \& Fawzi, W. W. (2015). Linear Growth and Child Development in Low- and Middle-Income Countries: A Meta-Analysis. Pediatrics, 135(5), e1266-e1275. https://doi.org/10.1542/peds.2014-3111

UNICEF, WHO, \& World Bank. (2018). Levels and Trends in Child Malnutrition, pp. 1-16. Retrieved from http://www.who.int/nutgrowthdb/2018-jme-brochure.pdf?ua=1\&ua=1

Uwiringiyimana, V., Ocké, M. C., Amer, S., \& Veldkamp, A. (2018). Predictors of stunting with particular focus on complementary feeding practices: A cross-sectional study in the Northern Province of Rwanda. Nutrition, 60, 0-7.

WHO. (2014a). What's at Stake. Who Int, (9), 1-10.

WHO. (2014b). Global nutrition targets 2025: Stunting policy brief.

WHO. (2019a). Feto-maternal nutrition and low birth weight. Rereieved from Https://www.who.int/nutrition/topics/feto_maternal/en/

WHO. (2019b). Breastfeeding of low-birth-weight infants. Rereieved from https://www.who.int/elena/titles/supplementary_feeding/en/

Wilcox, T., \& Hirshkowitz, A. (2015). NIH Public Access, 85(1), 1-27. https://doi.org/10.1016/j.neuroimage.2013.08.045.

Wondimagegn, Z. T. (2014). Magnitude and Determinants of Stunting Among Children in Africa a Systematic Review. Current Research in Nutrition and Food Science Journal, 2(2), 88-93. https://doi.org/http://dx.doi.org/10.12944/CRNFSJ.2.2.05

World Bank. (1994). World Development Report: Infrastructure for Development. New York: Oxford University Press. 